\title{
Repensando o modelo dos transportes públicos urbanos de passageiros: um olhar à gestão da demanda nas cidades de Maputo e Matola
}

Rethinking the model of urban public passenger transport: a look at demand management in the cities of Maputo and Matola

Revisión al modelo de transporte público urbano de pasajeros: Una mirada a la gestión de la demanda en las ciudades de Maputo y Matola.

Repenser le modèle des transports publics urbains de passagers : un aperçu de la gestion de la demande dans les villes de Maputo et Matola

\section{Nelson Mabucanhane}

\section{(2) OpenEdition}

Journals

Electronic version

URL: http://journals.openedition.org/espacoeconomia/4506

DOI: $10.4000 /$ espacoeconomia.4506

ISSN: 2317-7837

Publisher

Núcleo de Pesquisa Espaço \& Economia

Electronic reference

Nelson Mabucanhane, « Repensando o modelo dos transportes públicos urbanos de passageiros: um olhar à gestão da demanda nas cidades de Maputo e Matola », Espaço e Economia [Online], 13 | 2018, Online since 03 December 2018, connection on 02 May 2019. URL : http://journals.openedition.org/ espacoeconomia/4506; DOI : 10.4000/espacoeconomia.4506

This text was automatically generated on 2 May 2019.

(C) NUPEE 


\title{
Repensando o modelo dos transportes públicos urbanos de passageiros: um olhar à gestão da demanda nas cidades de Maputo e Matola
}

\author{
Rethinking the model of urban public passenger transport: a look at demand \\ management in the cities of Maputo and Matola \\ Revisión al modelo de transporte público urbano de pasajeros: Una mirada a la \\ gestión de la demanda en las ciudades de Maputo y Matola. \\ Repenser le modèle des transports publics urbains de passagers : un aperçu de la \\ gestion de la demande dans les villes de Maputo et Matola
}

\section{Nelson Mabucanhane}

\section{Introdução}

Os pressupostos teóricos que orientam as políticas governamentais de busca de equilíbrio entre a procura e a oferta de transportes público urbano de passageiro, têm sustento no estudo de Willian e Hall (1981) em 11 companhias americanas. Os autores mostram que para uma situação em que a oferta de transportes rodoviários urbanos de passageiros não satisfaz a procura, é preciso aplicar o modelo de operadores de grandes frotas ou transportes de massa. Aliás, este é o pressuposto básico da abordagem tradicional que aponta que a problemática dos transportes públicos urbanos de passageiros é assunto da engenharia e economia dos transportes. E por isso, o desequilíbrio entre a oferta e a procura é explicado a partir de quatro perspectivas tradicionais: engenharia de tráfego e segurança, planejamento e economia de transportes, logística e redes e infraestruturas de transportes, como defende Lindau, Ortúzar e Strambi (2000) e Viegas e Macário (2000). 0 
principal instrumento desta abordagem tradicional é a oferta quantitativa de autocarros de passageiros.

2 É neste contexto que o governo moçambicano tem vindo a desenhar políticas concentradas na teoria da oferta. Como é o caso, por exemplo, da fracassada tentativa de banir os transportadores com veículos com capacidade de 15 acentos para dar lugar aos transportadores com capacidade de 26 lugares ou acima. Ao lado desta estratégia, foram oferecidos subsídios aos transportadores licenciados a partir de fevereiro de 2008. Adicionalmente, foram desenhados e implementados vários modelos, como é o caso, por exemplo, do atual Plano 300, que disponibilizou veículos de grande capacidade para as empresas associadas à Federação Moçambicana dos Transportadores Rodoviários (FEMATRO); da ideia em curso do Metrô de Superfície; do Plano Bus Rapid Transit (BRT); Metro Bus e/ou o modelo dos antigos Transportes Públicos de Maputo (TPM) ou das atuais Empresas Municipais dos Transportes Públicos de Maputo e Matola, entre outras políticas governamentais e setoriais. O resultado destas políticas, programas e estratégias foi considerado pelos estudos da Agência dos Estados Unidos para o Desenvolvimento Internacional (USAID), em 2008, e pelo Instituto Superior de Transportes e Comunicação (ISUTC), em 2007, como um fracasso abismal e que de fato gerou os atuais "My loves".

3 Apesar de este artigo enfatizar a opção governamental por estas políticas, programas e estratégias apelam para uma análise estrutural do problema do desequilíbrio entre a oferta e a procura dos transportes públicos urbanos de passageiros. Aliás, os resultados do estudo de Walter (1968) em 66 operadores do Reino Unido mostraram que nem sempre a teoria de grandes frotas ou transportes de massa era garantia do equilíbrio entre a oferta e a procura, enquanto não forem considerados outros fatores estruturantes do sistema de transportes públicos urbanos de passageiros. É por esta via que as análises neste artigo se orientam. Trata-se do enfoque na abordagem moderna da sociologia urbana de cunho marxista. A sociologia urbana apela para o tratamento do problema dos transportes urbanos de passageiros de forma multidisciplinar e adoção de modelos ou políticas, programas e estratégias que permitam o gerenciamento da demanda controlável e administração dos Polos de Geração de Viagens (PGV's).

4 Metodologicamente, o artigo foi produzido a partir da revisão da literatura, análise documental e participação em seminários, palestras e entrevistas, questionários e conversas com autoridades, associações e passageiros em particulares alunos das escolas secundárias e alguns funcionários das instituições públicas.

\section{Breve contexto internacional dos transportes $r$ odoviários}

5 Os estudos especializados e/ou interessados pela análise do sistema de transporte registraram maior interesse após a Segunda Guerra Mundial (IIGM), Petters (1976), Haefele (1973), Owen (1975), Adler (1978). Tal interesse pode ser associado a dois fatores: a emergência da revolução dos transportes e à incapacidade destes para dar resposta às necessidades geradas pela industrialização, urbanização, aumento demográfico, migração desenvolvimento econômico e social. Sobretudo quando o estudo de Owen $(1975$, p.1) demonstrou que "o transporte deficiente é um fator decisivo para a fome mundial". Nesses estudos, é possível identificar duas abordagens principais: a abordagem tradicional e a abordagem moderna. 
O crescimento populacional, a industrialização e a urbanização são três principais fatores que não só demanda um sistema de transporte, mas imperam para um maior potencial de eficiência. De acordo com Petters (1976) em $1970^{2}$ existiam no mundo, $300 \times 10^{6}$ viaturas e $80 \times 10^{6}$ carros de carga para uma rede viária de $22 \times 10^{6}$ de diferentes categorias e funções, para uma população estimada em $4 \times 10^{9}$ milhões. Isto significa que existiam em cada $1 \mathrm{~km}$ de estrada 14 viaturas e 4 carros comerciais. Em média a relação passageiro / carro em cada 1.000 pessoas era de 70 passageiros para 1 carro, cuja performance era de $7.800 \times 10^{9}$ passageiros por km anualmente. A carga rodoviária anual foi estimada em média em $3.400 \times 10^{9}$ toneladas por km, "empregando cerca de $4 \%$ a $6 \%$ da população econômica ativa no setor dos transportes, em função do grau de desenvolvimento de cada país, do tipo de sociedade e do sistema político" (PETTERS, 1976, pp. 2-3).

7 O crescimento industrial, a urbanização e o aumento da população implica maior demanda de transporte, cuja taxa de mobilidade continua um problema tremendo. Em função da taxa de motorização, Haefele (1973) subdividiu as regiões mundiais em móveis e imóveis. Até 1975 a Ásia, África e América Latina continham 71\% da população mundial, mas dispunham de apenas $15 \%$ e $17 \%$ do transporte ferroviário e rodoviário mundial, respectivamente e o resto era detido pela América do Norte, Europa e Austrália. No mesmo período o Canadá tinha o maior índice de mobilidade de $148.9^{3}$, seguido pelos Estados Unidos da América (EUA) e Dinamarca com 147.2 e 11.7, respectivamente e a Etiópia detinha 1.7, o índice mais baixo, dos 53 países estudados.

8 Embora a migração das pessoas das zonas rurais às cidades seja maior nas regiões com maior taxa de mobilidade, a demanda de transporte é mais aguda em termos de acesso nas regiões de menor taxa de mobilidade. Dado que as cidades das regiões com menor taxa de mobilidade recebem, em termos absolutos mais pessoas do que nos países desenvolvidos. Primeiro por que têm menor número de pessoas e segundo porque diversificaram enormemente as cidades em quase todo o território. A maioria dos países pobres da África, Ásia, América Latinas e Caraíbas só têm como cidade as precárias capitais em termos de infraestruturas que são na verdade herança colonial. Assim, o êxodo rural é unidirecional, ou seja, das diversas zonas rurais para a única cidade capital. Essas cidades não só não estão preparadas para receber tanta gente ao mesmo tempo (anos 90 em diante) em termos de planejamento físico territorial, como também registram gravíssimos problemas de rede viária para além do crônico problema de transportes públicos urbanos de passageiros. Muitas das capitais africanas e algumas cidades locais continuam a sobreviver, em termos de infraestruturas, das ruínas coloniais, cuja gravidade foi aumentada em alguns países pelas guerras civis, como por exemplo, Moçambique, Cabo Verde, Guine Bissau e Angola.

9 Em termos absolutos "entre 1970 a 2011 a população mundial aumentou de 3.600 para 7.000 bilhões, porém, à medida que a população se torna mais instruída, a sua taxa de crescimento abrandava" (PNUD, 2013, p. 11). Desde 2011 a população mundial é estimada pela ONU (2012) e ONU (2013) em 7.2 bilhões e há uma expectativa de que esta alcançará 10.9 até 2100 . Estes dados não só representam o volume das necessidades produtivas industriais, agrícola, como também, o crescimento da população urbana e as demandas de transportes públicos urbanos de passageiros.

10 De acordo com o mapa do Fundo das Nações Unidas para Infância (UNICEF) de 2012, 40 países no mundo apresentam uma taxa de urbanização acima de 75\% do território, contra 15 países com o grau de urbanização abaixo de $25 \%$, majoritariamente localizados na África e os restantes se situam entre $25 \%$ a $75 \%$ e $25 \%$ a 50\% na sua taxa de urbanização. 0 
relatório publicado pelo Conselho Nacional de Inteligência Americana em 2012 aponta que até 2030, 4.9 bilhões de pessoas poderão viver nas cidades. Atualmente, de acordo com a Conferência das Nações Unidas Rio + 20 e o relatório do Departamento dos Assuntos Sociais e Econômicos das Nações Unidas de 2013, a população urbana é estimada em 3.6 bilhões, ou seja, 50\% da população mundial vivem nas cidades desde 2007. As projeções do crescimento da população urbana africana e asiática apontam para um aumento de 414 milhões em 2007 para 1.2 bilhão, em 2015. Podendo passar para 1.9 bilhão em 2030 e 3.3 bilhões até 2050. Estes dois continentes poderão representar $86 \%$ do total do crescimento populacional mundial em 2050. O crescimento urbano e da população urbana pressionam de forma incisiva o setor dos transportes porque é por meio deste que se pode processar igualmente, a redução da pobreza, o acesso aos mercados, aos locais de trabalho, ao transporte de bens, entre outras e inumeráveis finalidades do transporte.

11 Relativamente à análise dos transportes públicos urbanos de passageiros, a abordagem tradicional, ao estudo a mobilidade urbana afirma que esta é matéria específica da engenharia dos transportes e economia dos transportes. Neste sentido, a metodologia aplicada é exclusivamente quantitativa, como atestam os estudos de Lindau, Ortúzar e Strambi (2000) e Viegas e Macário (2000). Estes e mais estudos quantitativos, focalizam quatro áreas tradicionais: engenharia de tráfego e segurança; planejamento e economia de transportes; logística e redes viárias e infraestruturas de transportes. Para esta abordagem, a ineficiência do sistema de transportes é explicada no campo da engenharia e da economia de transporte, pelas falhas dos modelos técnicos de estimação, de provisão quantitativa das infraestruturas viárias e da oferta das viaturas. E a terapia para este problema é a oferta de infraestruturas viária e de viaturas. Esta defesa encontrou no estudo e Willian e Hall (1981) um suporte teórico de magnitude desejada, dado que, para estes autores, para uma situação em que a oferta de transportes não satisfaz a procura é preciso aplicar a teoria de grandes frotas ou transportes de massas.

Todavia, com emergência das teorias neoliberais e a perene confiança nas forças do mercado para a distribuição do bem-estar, a fase de estimação e de previsão da abordagem tradicional, entrou em crise. A rejeição deu lugar a novos enfoques de redimensionamento, tanto da metodologia quanto do alargamento dos campos de estudo. É assim que nos anos 70, surgem estudos sobre a sociologia urbana, com destaque, como aponta Vasconcellos (2001), os tirocínios trabalhos de Healey (1977), aos quais se podem acrescer no trabalho de Haefele (1973).

Para além disso, o estudo e Walter (1968) no Reino Unido mostrou que a teoria de grandes frotas e de transportes de massa nem sempre era aplicável a todos os contextos sociais e econômicos. Assim, surge a abordagem moderna cuja metodologia analítica já não é exclusivamente quantitativa, mas também, qualitativa e o seu enfoque é a sociologia urbana no contexto da mobilidade humana, principalmente nas grandes metrópoles. A lógica subjacente neste novo paradigma é de que a ineficiência do sistema de transportes pode estar associada ao processo distributivo da renda, à deficiente programa de planejamento urbano, ao controle da migração, ao desajustamento dos programas de desenvolvimento econômico e social de longo prazo, etc. A sociologia urbana, demonstrou que os estratos sociais que demandam o transporte urbano de passageiros tendem a residir nas zonas periféricas. E por isso, a ineficiência dos transportes não é um problema tecnicista de provisão de redes viárias, de viaturas, mas sim, é também, um problema estrutural de planejamento urbano que demanda um programa a longo prazo de 
desenvolvimento econômico, social e da configuração dos Polos de Geração de Viagens (PGV's) sobretudo nos grandes centros urbanos.

Para Vasconcellos (2001, p.19) e Portugal (2012), a novidade da abordagem moderna é o seu potencial multidisciplinar, dado que as ineficiências dos transportes não se localizam exclusivamente nas falhas técnicas da engenharia e economia dos transportes. Mas sim, podem ser explicadas, por exemplo, pela sociologia urbana, pelas ciências políticas, antropologia, religião, etc. A contribuição desta nova abordagem é, de acordo com Owen (1975, p.59), ter demonstrado que as necessidades de transporte são geradas pelo que acontece para além do campo dos transportes. E por isso, o exercício de estimação da rede viária, de provisão dos transportes não será eficaz e eficiente enquanto ignorar os fatores que geram as necessidades de transporte. Apesar desta verdade, a reação dos teóricos da abordagem tradicional foi dura e o principal argumento é, de acordo com Town (1981), de que a oferta do transporte é uma ação pragmática baseada em técnicas de engenharia de tráfego e segurança, de planejamento urbano e economia de transportes, de logística de redes e de infraestruturas de transportes e, sobretudo, de oferta de grandes frotas de transportes de massa.

\section{Contexto nacional da problemática dos transportes públicos urbanos de passageiros}

15 Estudos realizados em Moçambique pelo Instituto Superior de Transportes e Comunicação (ISUTC), em 2007, e pela Agência dos Estados Unidos para o Desenvolvimento Internacional (USAID), em 2008, associam o fracasso da oferta dos transportes urbanos de passageiros à desproporcionalidade entre as inflexíveis e duradouras tarifas de operação definidas pelo governo, com o poder destas tarifas para assegurar a manutenção e desenvolvimento expansionista das companhias operadoras. A USAID (2008) mostra ainda que em 2008 dos 35 autocarros dos Transportes Públicos de Maputo (TPM), que circulam num dado dia, 7 a 8 registravam avarias. Aliado à menor capacidade de manutenção destas viaturas, mais de $50 \%$ saíam da rota de circulação por ano, reduzindo deste modo a capacidade de oferta. As inflexíveis tarifas de operação dos transportadores, o desprezível grau de capitalização das associações, das cooperativas e demais operadores não só lhes impediu de expandir a frota dos autocarros, como também, lhes retirou do negócio. 0 que explica a entrada no negócio de transporte de passageiros das carinhas de caixa aberta e camionetas, os vulgos "my loves", cujo pico operativo foi registrado entre 2014 a 2017.

Associa-se ao problema acima levantado o problema das infraestruturas viárias. De acordo com o Instituto Nacional de Estatística (INE), até 2009, 77\% das estradas moçambicanas eram intransitáveis ou apresentavam más condições de transitabilidade. Este fato e os baixos lucros arrecadados pelos transportadores podem explicam a saída anual de operadores de transportes.

17 De forma paralela, o governo moçambicano não só é agente econômico no sistema de transportes de passageiros nacionais, como também, oferece transportes de instituições específicas que transportam, exclusivamente os funcionários das diversas instituições públicas. Todavia, tais autocarros só levam funcionários do ministério ao qual pertencem, o que gera injustiça, uma vez que existem dentro da mesma administração pública, funcionários que não têm acesso a esses transportes, como é o caso, por exemplo, dos professores, uma parte dos funcionários da saúde, os polícias e outras instituições sem 
autocarro institucional. Estes funcionários excluídos recorrem às paragens para chegar ao serviço, o que aumenta os concorrentes, a demanda ou a disputa pelos transportes públicos urbanos de passageiros. Para além da injustiça que isso gera, o custo de operação destes autocarros institucionais de pessoal é demasiadamente elevado. Em duas instituições, o Instituto Superior de Administração Pública (ISAP) e Ministério dos Transportes e Comunicações (MTC), por exemplo, foi possível perceber que os custos de combustível, de manutenção e outras despesas entre Janeiro a Maio de 2018, estão acima de 500.000 MT, por mês. O mais paradoxal nisto, é que esses autocarros não estão distribuídos por corredores de operação, o que faz com que percorram quase todas as artérias das cidades de Maputo - Matola e província, alargando os custos de operação e por vezes, transportando menor capacidade de passageiros. Isto por que os funcionários afetos a esse autocarro só o apanham quando não tiverem alternativas para se fazer ao serviço e vice-versa. O mais crítico no uso destes autocarros de acordo com alguns entrevistados é ter que acorda muito cedo e dar volta por toda a cidade durante o recolhimento dos demais colegas.

18 A ociosidade, os elevados custos de operação destes autocarros institucionais e o fato de serem agentes que geram congestionamento em várias artérias viárias e a injustiça que representam obriga a análise de novos modelos. No contexto da sociologia urbana e da abordagem moderna é preciso conjugar a lógica de ação tecnicista e pragmática, dos problemas de mobilidade urbana não apenas a cálculo econômico, e de ineficiência técnica, ou seja, sair-se da ideia de que a inoperância dos transportes é um problema da oferta e administração da rede viária e dos transportes públicos para uma visão estrutural do problema.

19 A mudança de paradigma, ou seja, de autocarros institucionais que levam funcionários específicos para autocarros do Estado capazes de levar qualquer funcionário pode reduzir os concorrentes nas paragens de transportes públicos. Nesse modelo, deve se criar corredores aos quais certo número de autocarros irá operar em função da quantidade de funcionários públicos. Devem-se instalar aparelhos eletrônicos com capacidade para ler a impressão digital previamente sincronizada de cada um dos funcionários de modo a evitar a entrada de outras pessoas que não sejam funcionários públicos. Este modelo tem uma multiplicidade de vantagens, entre as quais se podem destacar: i) redução dos concorrentes de transportes públicos urbanos de passageiros nas paragens; ii) a eliminação de injustiça entre os funcionários do mesmo Estado, uma vez que existe atualmente, funcionários que não têm acesso a nenhum autocarro institucional; iii) a redução dos custos de operação e de manutenção, uma vez que os autocarros apenas circulam em rotas ou corredores dedicados. $\mathrm{O}$ que acaba diminuindo o engarrafamento das atuais artérias às quais circulam.

Outro modelo de redução dos concorrentes nas paragens ou de gerenciamento da demanda controlável é o enfoque aos alunos das escolas secundárias e/ou técnico profissionais públicas. Através de um dispositivo legal o Ministério da Educação e Desenvolvimento Humano pode regular que os alunos das escolas secundárias e do ensino técnico profissional sejam matriculados o mais perto possível de suas residências. Foi realizado no contesto deste estudo, uma observação nas paragens em dois momentos distintos. Num dos momentos, os alunos estavam de aulas e no outro estavam de férias. Qualquer observador atento, nas cidades de Maputo e Matola irá concordar com a conclusão de que as paragens e as únicas redes viárias estão relativamente menos congestionadas quando os alunos estiverem de férias. Esta conclusão permite perceber 
que um dos agentes de congestionamentos das paragens é o aluno e por isso, qualquer política ou modelo de oferta deve ter em conta estes alunos. A obrigatoriedade de matricular os alunos o mais próximo possível das zonas de residência visa diminuir a sua presença nas paragens, o que lhes retira igualmente dos cíclicos acidentes rodoviários.

21 À título experimental, foram realizadas entrevistas com 449 alunos das escolas secundárias da Matola e Josina Machel, da $9^{\mathrm{a}}$ e $12^{\mathrm{a}}$ classes, respectivamente. Os resultados desse ensaio mostraram que 284 alunos (63.3\%) residiam perto de uma escola secundária do mesmo ciclo. Desses alunos, 146 (32.5\%) afirmaram depender de ligações para chegar ao destino. E apenas 125 (27.8\%) afirmaram que para chegar à escola não precisavam de transporte por que a escola fica perto de casa. Ao analisar os bairros proveniência desses alunos foi possível constatar que os da Escola Secundária Josina Machel são Costa do Sol, Hulene, Polana Caniço, Albasine, Malanga, Jardim, cidade da Matola, etc. E para o caso da Escola Secundária da Matola a maioria reside nos bairros da Liberdade, Tchumene, Matola Godinho e Fumento. Apesar de não ser a maioria, foram encontrados alunos que estudam na Escola Secundária da Matola a residir nos bairros de T3, Zona Verde, Jardim, Alto Maé, Costa do Sol, etc. E na Escola Secundária Josina Machel foram igualmente encontrados em número reduzido, alunos provenientes dos bairros como Liberdade, Matola A, C; Jardim, etc.

Estes resultados obrigam a realização de um estudo mais profundo capaz de determinar se nas zonas de residências nas quais existe uma escola do mesmo ciclo não é ou não possível encaixar estes alunos, ainda que se faça por via de permuta com os seus homólogos das demais escolas. Para facilitar essas permutas é preciso que os computadores das secretarias das escolas sejam equipados de software capazes de agrupar os alunos por bairros e haja uma consolidada relação de comunicação entre as escolas. O que havia de permitir a transferências desses alunos.

Durante os debates nas III Jornadas Científicas do ISAP, assim como as entrevistas com os alunos, alguns encarregados de educação afirmaram à semelhança dos estudantes que se sente satisfeito por ver os seus educandos a frequentar escolas com certa reputação. Para além disso, foi colocada a questão de que a cidadania se faz nas cidades e por isso os alunos devem ser matriculados nas melhores zonas urbanas. Apesar de os vários argumentos levantados serem perceptíveis é preciso afirmar que uma política alocativa dos alunos havia de: i) reduzir a vulnerabilidade destes aos acidentes rodoviários; ii) reduzir os concorrentes dos transportes públicos urbanos nas paragens, e; iii) obrigar o governo a oferecer uma cesta básica equilibrada de qualidade e condições de ensino nas escolas públicas.

24 Embora estes dados sejam particulares são fundamentados pelo relatório do Conselho Municipal da Cidade de Maputo, juntamente com a Agência de Cooperação Internacional do Japão de 2001, que aponta que aproximadamente $40 \%$ dos passageiros num universo de 2.264 entrevistados, precisavam de 2 ou mais autocarros para completar uma única viagem. $O$ relatório aponta que $60.6 \%$ dos entrevistados usa apenas um autocarro para chegar ao destino, $36.6 \%$ usam dois autocarros e apenas $2.8 \%$ preciso de três autocarros. Em termos de frequência de viagens semanais, o relatório aponta 5 a 7 vezes por semana (63.6\%); 3 a 4 vezes por semana (7.6\%); uma vez e duas vezes por semana (14.7\%) e menos de uma vez por semana (14.1\%). Paradoxalmente, o relatório ao caracterizar os passageiros, aponta que estes na sua maioria são trabalhadores formais, informais ou a conta própria. Paradoxalmente, no sentido de que não faz referência aos alunos. No ensaio observacional feito no contexto deste estudo nas paragens mostro a situação acima 
descrita, ou seja, paragens demasiadamente congestionadas durante o período letivo e menos congestionadas quando estes estiverem de férias. Aliás, não precisa ser pesquisador para perceber este fato, dado que mesmo o engarrafamento diminui a proporções bem elevadas e é estranho que o relatório do Conselho Municipal de Maputo juntamente com a JICA de 2001, não tenha incluso os alunos nas suas entrevistas. Apesar destes dados do relatório refletir uma realidade vivida nas cidades de Maputo e Matola, o conceito de ligações ao que se referem, não é realístico. Dado que nas horas da ponta, a preocupação dos passageiros com algum poder econômico ao seu nível, não é se existe ou não um autocarro que lhe leve do ponto X para $Y$, mas sim, em que condições irá fazer essa viagem. E por isso, independentemente de ser uma distância que justifique fazer ligações, os passageiros são obrigados através das estratégias "cobradistas (do cobrador)" a efetuar ligações. Existem vários fatores que expliquem essas estratégias "cobradistas", mas a questão tarifária é um deles. Ou seja, o custo de operação dos transportes públicos de passageiros não é capaz de permitir a um operador compensar os custos e garantir a expansão da sua frota, para além do lucro que deseja.

Outros agentes concorrentes das paragens são gerados pelos trabalhadores do setor privado. Estes trabalhadores das empresas privadas constituem, à semelhança dos funcionários e agentes do Estado e dos alunos, a demanda controlável. E por isso, mais do que o governo concentrar suas políticas em oferecer paraísos fiscais a megaprojetos que pouco contribuem para as finanças públicas, devia oferecer incentivos fiscais às pequenas e médias empresas que constituem o segundo maior empregador depois do Estado. Tais incentivos visariam induzir as empresas a oferecer aos seus trabalhadores transportes, $o$ que retiraria estes das paragens.

Os Polos de Geração de Viagens (PGV's) são outro foco na adoção de políticas estruturais para a problemática dos transportes públicos urbanos de passageiros nas cidades de Maputo e Matola. A partir da abordagem moderna conjugada com a sociologia urbana de cunho marxista, este artigo defende a gestão da demanda controlável, ou seja, a formulação de políticas estruturais de gerenciamento dos passageiros e dos Polos de Geração de Viagens (PGV's). A desconcentração dos PGVs (em particular, as universidades, escolas secundárias privadas e públicas, supermercados, shoppings, ...) é outra forma de controlo gerencial da demanda. A desconcentração dos PGVs do centro da cidade para os bairros periféricos densamente habitados, não deve ser tomada ao "pé da letra", mas no sentido de que não se deve mais licenciar este tipo de infraestruturas no centro da cidade. Mas para tal é preciso implementar políticas de incentivo fiscal e outros atrativos como infraestruturas nas zonas periféricas. A vantagem da desconcentração dos PGV's é permitir que o fluxo de passageiros seja bidirecional, sobretudo nas horas de ponta. $\mathrm{O}$ que havia de permitir a arrecadação de receitas pelos operadores privados. A construção, por exemplo, do Mercado Grossista, do Estado Nacional, do Instituto Superior de Relações Internacionais (ISRI), entre outras infraestruturas públicas e privadas no bairro de Zimpeto gerou passageiros que saem da cidade de Maputo, Matola, entre outros locais, para este centro comercial e institucional. o fluxo bidirecional dos passageiros capitaliza dos operadores, o que poderá gerar lucro, caso o governo delegue às forças do mercado o ajuste tarifário.

Operadores capitalizados podem oferecer múltiplas vantagens para o país e para os utentes: i) oferecer serviços de qualidade (acesso, flexibilidade, conforto e eficiência); ii) capacidade expansionista da oferta de serviços para outros locais; iii) o transporte de pessoas e bens é condição obrigatória para o dinamismo econômico; iv) capacidade de 
manutenção e aumento das frotas de viaturas. Como se disse, no atual modelo e sobretudo com as baixíssimas tarifas pagas pelos passageiros como consequência da exagerada regulamentação governamental, qualquer operador descapitalizado não poderá sobreviver. Aliás, Moçambique tem a memorável experiência dos TPM que apesar de constantes incrementos de autocarros por parte do governo, não eram capazes de cobrir as suas despesas, como por exemplo, salariais, de operação, entre outros e o déficit chegava a $56 \%$.

No segundo volume do seu livro sobre o sistema de transportes, Novaes (1986) observa que o transportador somente é estimulado a aumentar os níveis da oferta quando o preço for crescente. No contexto desta pesquisa, isso não significa aumentar a tarifa dos transportes, mas, sobretudo, a lucratividade através do estudo dos mecanismos de gerenciamento da eficácia e da eficiência. Ou seja, quais são as formas de gerenciamento e administração do atual sistema de transportes públicos nas cidades de Maputo e Matola, que mesmo mantendo constante a tarifa, os carros existentes, a rede viária seja possível incrementar, proporcionalmente a eficiência e o lucro? A ineficiência do sistema de transportes não é apenas um problema de ação tecnicista e pragmática de engenharia, de cálculo econômico, e de inoperância técnica como defende a abordagem tradicional ou de aumento ou diminuição da tarifa em função dos fatores do mercado como crê Novaes (1986), mas também, um problema de modelo gerencial da demanda e dos PGVs. É este o modelo que esta pesquisa pretende testar a sua aplicabilidade nos Municípios de Maputo, Matola, Marracune e Boane, a chamada Região Metropolitana de Maputo.

\section{Considerações finais}

O objetivo do presente artigo foi de analisar a abordagem teórica que orienta os modelos ou políticas governamentais, na busca de equilibrar entre a procura e a oferta dos transportes públicos urbanos de passageiros nas cidades de Maputo e Matola. A pergunta de investigação foi que políticas ou modelos são necessários para as cidades em questão, de modo a equilibrar a procura e oferta dos transportes públicos urbano de passageiros? Ou por outras, como garantir a eficácia e eficiência do sistema de transportes públicos urbanos de passageiros considerando a escassez de recursos financeiros? O principal argumento que orientou este artigo foi de que a opção governamental pelas políticas ou modelos de gestão da oferta de novos autocarros de transportes públicos urbanos de passageiros, não é suficiente por si só, para garantir o equilíbrio entre a procura e a oferta sem ter em conta as políticas de gerenciamento da demanda controlável, considerando que o problema é estrutural.

31 Apesar de a pesquisa propriamente dita não ter sido completada, sobretudo no que diz respeito ao trabalho de recolha de dados nas instituições pública e privadas, nas paragens de autocarros, nas autoridades governamentais, entre outros, a análise teórica permite validar o argumento deste artigo. Os resultados desta análise permitem concluir que a conjugação da abordagem tradicional (concentrada na oferta - atual modelo governamental) com a abordagem moderna, ou seja, aquela que defende políticas estruturais de gerenciamento da demanda controlável (alunos, funcionários e trabalhadores das empresas privadas) pode reduzir o sofrimento dos munícipes das duas cidades. Uma vez que problemas estruturais devem ser analisados e resolvidos através da formulação de modelos e políticas estruturantes. Os múltiplos benefícios da conjugação de abordagens incluem os seguintes resultados: i) reduzir a demanda dos transportes 
públicos urbanos de passageiros nas paragens; ii) reduzir os custos de operação dos autocarros institucionais, sobretudos em termos de combustível, uma vez gerenciadas as rotas de circulação. Adicionalmente, é possível que seja diminuída a circulação destes autocarros institucionais em algumas artérias considerando que os funcionários residentes nessas zonas estarão agrupados num certo corredor. A geração de um modelo e/ou política que permite que todos os funcionários do Estado tenham acesso aos autocarros dedicados no seu corredor, permite a redução da atual injustiça uma vez que as os funcionários das instituições sem autocarros fazem-se ao serviço a custo próprio, congestionando as paragens, e; iii) a adoção pelo Ministério da Educação e Desenvolvimento Humano de uma política que obrigue aos alunos das escolas secundárias e técnicas profissionais públicas a se matricularem o mais próximo de casa pode reduzir igualmente a demanda nas paragens de autocarros.

\section{BIBLIOGRAPHY}

ADLER, H. A. Avaliação Econômica dos Projetos de Transportes: Metodologia e Exemplos. Tradução: Heitor Lisboa de Araújo, Livros Técnicos e Científicos Editora, Rio de Janeiro, 1978.

Agência de Cooperação Internacional do Japão e Conselho Municipal da Cidade de Maputo. Estudo sobre Plano Director e Estudo de Viabilidade para o Desenvolvimento de Estradas da Cidade de Maputo na República de Moçambique, Relatório Final, n³2, Maputo, 2001.

COSTA, A. H. Manual de Planeamento de Acessibilidade e Transportes Públicos. Universidade do Porto, Portugal, 2008.

DISENYANA, T. and KHUMAO, N. Transport Services in SACU: Accelerating Harmonisation and Liberalisation.University of the Witwatersrand, Braamfontein Johannesburg, South Africa, 2009.

GONÇALVES, F.dos S. e tal. Caraterização dos Polos Geradores de Viagens. IN: PORTUGAL, L. da S. (Org.) et al. Polos geradores de viagens orientados a qualidade de vida e ambiental: Modelos e taxas de geração de viagens, Editora Interciência Ltda, Rio de Janeiro, 2012.

HAEFELE, E. (Coord.) et al. Transportes e Objetivos Nacionais. Tradução: Noel Gertel, $1^{\mathrm{a}}$ edição, Editora: Fundação Getulio Vargas, Rio de Janeiro, 1973.

HUBER, M. J. Traffic Flow Theory. IN: INSTITUTE OF TRANSPORTATION ENGENEERS.

Transportation and Traffic Engineering Handbook. Second Edition, United States of America, 1976.

LINDAU, L. A; ORTÚZAR, J. de D. e STRAMBI, O. (ed.) et al. Engenharia de Tráfego e Transportes 2000: avanços para uma era de mudanças - IX Congresso Pan-americano de Engenharia de Trânsito e Transporte, editores ANPET, Rio de Janeiro, 2000.

United States of America. Global Trends 2010: Alternatives Worlds. Disponível em: <www.dni/gov/ nic.globaltrends>. Acesso em 13 Mai. 2014.

NOVAES, A. G. Sistema de Transportes: Análise da Demanda. Vol. 1, Editora Edgard Blücher LTD, São Paulo, 1986. 
. Sistema de Transportes: Análise da Oferta. Vol. 2, Editora Edgard Blücher LTD, São

Paulo, 1986.

. Sistema de Transportes: Equilíbrio Oferta-Demanda. Vol. 3, Editora Edgard Blücher LTD, São Paulo, 1986.

OLIVEIRA, M. E. de. Pensando como um economista: síntese de reflexões. eBooksBrasil.com, São Paulo, 2010.

OWEN, W. Estratégia para os Transportes, Tradução de David H. Hastings, Livraria Pioneira Editora, São Paulo, 1975.

PETTERS, H. J. Transportation and society. IN: INSTITUTE OF TRANSPORTATION ENGENEERS. Transportation and Traffic Engineering Handbook. Second Edition, United States of America, 1976.

PORTUGAL, L. da S. (Org.) et al. Polos geradores de viagens orientados a qualidade de vida e ambiental: Modelos e taxas de geração de viagens, Editora Interciência Ltda, Rio de Janeiro, 2012.

United Nations, Department of Economic and Social Affairs, Population Division. World Population 2012. Disponível em: <http://www.unfpa.org/public/world-population-day>.Acesso em: 18 Agos.2014].

Department of Economic and Social Affairs. World and Economic and Social Survey 2013: Sustainable Development Challenges, New York, 2013. Disponível em: <http://www.un.org/en/ development/desa/policy/wess/wess_current/wess2013/WESS2013.pdf>. Acesso em 18Agos.2014].

. UNICEF.Children in an Urban World: The State of the World's Children 2012 Children in an Urban World.Disponível em: <http://www.un.org/ru/publications/pdfs/state\%20of\%20the\% 20world's\%20children\%202012_children\%20in\%20an\%20urban\%20world.pdf>.Acesso em: 21Agos.2014].

VASCONCELLOS, E. A.Transporte urbano, espaço e equidade: análise das políticas públicas, $2^{\underline{a}}$ edição, São Paulo, 2001.

VIEGAS, J. M. e MACÁRIO, R. Financiamento da Mobilidade Urbana: Como escolher Alternativas? IN: LINDAU, Luis Antonio; ORTÚZAR, Juan. de Dios e STRAMBI, Orlando (ed.) et al. Engenharia de Tráfego e Transportes 2000: avanços para uma era de mudanças - IX Congresso Panamericano de Engenharia de Trânsito e Transporte, editores ANPET, Rio de Janeiro, 2000.

WALTERS, J. (1968). Overview of Public Transport Policy Developments in South Africa. Department of Transport and Supply Chain Management, University of Johannesburg.

Williams, M. L. and Hall, C. (1981). Returns to scale in the United States Intercity bus industry Regional Science and Urban Economics. Disponível em: https://www.sciencedirect.com/science/ article/pii/0166046281900399, Acesso em 13 de Agosto de 2013.

\section{NOTES}

1. Expressão usada em Moçambique para designar carinhas e camionetas de caixa aberta que transportam passageiros, sobretudo nas horas de ponta. Trata-se de carinhas e camionetas sem licenças e com precárias condições de segurança para transportar pessoas, o que tem resultado muitas vezes em mortes. Atenção que este artigo é uma parte de um estudo que ainda está em curso conduzido pelo mesmo autor e que irá abranger os municípios de Maputo, Marracuene, Matola e Boane.

2. 1970 é o marco histórico da revolução dos transportes. 
3. De acordo com Owen (1975, p. 10) a Organização das Nações Unidas (ONU), Statistical Yearbookatravés International Road Fundation, World Highway Statistcs, 1960, os países com índice abaixo e acima de 30 foram classificados, respectivamente por imóveis e móveis. Nessa altura, Brasil e Portugal com 19,8 e 27,7, na mesma ordem, foram qualificados como imóveis.

\section{ABSTRACTS}

With the objective of analyzing the theoretical approaches that guide the models or policies that have been carried out by the Mozambican government in order to balance the demand and the supply of urban public passenger transport in the cities of Maputo and Matola, this article was produced. The starting question was what policies or models are needed for the cities of Maputo and Matola in order to balance the demand and supply of urban public passenger transport? Or by others, how to guarantee the effectiveness and efficiency of the urban public transport system of passengers in the cities of Maputo and Matola considering the scarcity of financial resources? The main argument of this article is that the government's choice of policies or models for the management of the supply of new urban public passenger transport buses is not sufficient in itself to ensure a balance between demand and supply without taking into account the controllable demand management policies, considering that the problem is structural. The search for empirical evidence to support this argument was based on literature review and documentary analysis. And from a theoretical point of view, the article considers that, rather than guiding urban public passenger transport policies from the traditional approach, one must also consider the modern approach to urban sociology of a Marxist nature.

Com o objetivo de analisar a aplicabilidade das abordagens teóricas que orientam os modelos ou políticas que têm sido levados a cabo pelo governo de Moçambique, de modo a equilibrar a procura e a oferta dos transportes públicos urbanos de passageiros nas cidades de Maputo e Matola, foi produzido o presente artigo. A pergunta de partida foi a de que políticas ou modelos são necessários para equilibrar a procura e oferta dos transportes públicos urbanos de passageiros? Ou, em outro sentido, como garantir a eficácia e eficiência do sistema de transportes públicos urbanos de passageiros nas cidades em estudo, considerando a escassez de recursos financeiros? o principal argumento deste artigo aponta que a opção governamental pelas políticas ou modelos de gestão da oferta de novos autocarros de transportes públicos urbanos de passageiros não é suficiente, por si só, para garantir o equilíbrio entre a procura e a oferta, sem ter em conta as políticas de gerenciamento da demanda controlável. Assim, consideramos que o problema é estrutural. As evidências empíricas para sustentar este argumento basearam-se na revisão da literatura e análise documental. E, do ponto de vista teórico, o artigo considera que mais do que orientar as políticas de transportes públicos urbanos de passageiros a partir da abordagem tradicional é preciso considerar, também, a abordagem moderna da sociologia urbana de cunho marxista.

Este artículo, pretende analizar los modelos teóricos que orientan las políticas aplicadas por el gobierno de Mozambique, para equilibrar la oferta y la demanda del transporte público en las ciudades de Maputo y Matola.

La pregunta de partida esta en la determinación de cuales son los modelos necesarios para equilibrar la relación de oferta y demanda. Derivada de la anterior, se analiza la eficacia y la 
eficiencia de las políticas propuesta en un contexto de escasez de recursos financieros. El principal argumento de esta investigación, apunta que la gestión de la oferta a partir de los nuevos autobuses es insuficiente para resolver el problema, pues no tiene en cuenta el gerenciamiento de la demanda, dejando fuera una parte de un problema que es estructural. La evidencia aquí presentada es de tipo empírico y fue hecha a partir de una revisión de literatura y análisis documental.

Bajo el punto de vista teórico, la consideración va más allá de orientar la política pública de transporte urbano desde una perspectiva tradicional, para proponer otros enfoques desde la sociología urbana de tipo marxista.

Cet article a été élaboré dans le but d'analyser les approches théoriques qui conditionnent les modèles adoptés ou les politiques mises en œuvre par l'État du Mozambique, afin d'équilibrer l'offre et la demande en matière de transports urbains publics de passagers, dans les villes de Maputo et Matola. La question initiale était de savoir quelles politiques ou quels modèles les villes de Maputo et Matola devaient adopter, afin d'équilibrer l'offre et la demande en matière de transports publics urbains de passagers. En d'autres termes, comment garantir l'efficacité du système de transports publics urbains de passagers dans les villes de Maputo et Matola, comptetenu du manque de moyens financiers? Le principal argument de cet article est la mise en évidence du fait que les choix faits par l'État en matière de politiques ou de modèles de gestion de l'offre de nouveaux autobus destinés au transport public urbain de passagers ne suffit pas à elle seule à garantir l'équilibre entre l'offre et la demande, sans que l'on ait à brider les politiques de gestion de la demande contrôlable, compte-tenu du fait que le problème est structurel. Pour étayer cet argument, nous avons cherché des preuves empiriques en procédant à une révision des textes et à une analyse des documents. Et, d'un point de vue théorique, on considère qu'au lieu de ne définir les politiques relatives aux transports publics urbains en qu'à partir d'une approche traditionnelle, il faudrait également tenir compte de l'approche moderne que propose la sociologie urbaine à caractère marxiste.

\section{INDEX}

Mots-clés: modèle de transports publics urbains de passagers ; gestion de la demande de transports.

Keywords: urban public passenger transport model; demand management of transport. Palabras claves: modelo de transporte público de pasajeros, gestión de la demanda del transportes.

Palavras-chave: modelo de transportes públicos urbanos de passageiros; gestão da demanda de transportes.

\section{AUTHOR}

\section{NELSON MABUCANHANE}

Doutor em Políticas Públicas, na Linha de Estado e Políticas Pública pela Universidade do Estado do Rio de Janeiro e Mestre em Gestão de Políticas Públicas pela Peking University-China. É docente no Instituto Superior de Administração Pública em Moçambique. 